\title{
Author Correction: Meta-analytic research of the dose-response relationship between salt intake and risk of heart failure
}

Satoru Kodama - Chika Horikawa - Kazuya Fujihara - Mariko Hatta • Yasunaga Takeda - Rena Nedachi • Kiminori Kato - Kenichi Watanabe - Hirohito Sone

Published online: 25 March 2021

(C) The Japanese Society of Hypertension 2021

Correction to: Hypertension Research https://doi.org/10.1038/s41440-021-00632-2

Published online 02 March 2021

In the version of this article originally published, Supplementary Figure contained several errors. The corrected figure is shown below.

The original article has been corrected.

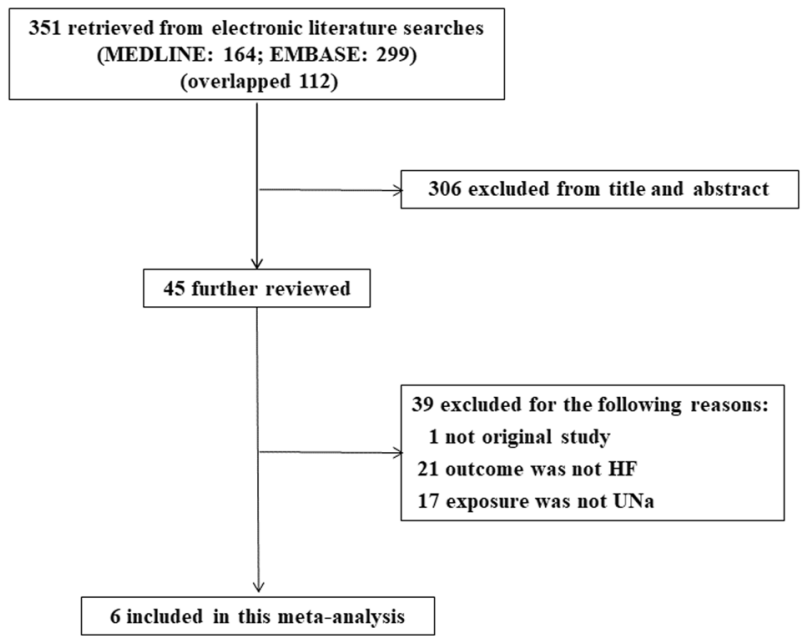

Abbreviations: HF, heart failure; UNa, 24-h urine $\mathrm{Na}$ excretion 